\title{
Belief Structures, Common Policy Space and Health Care Reform: A Q Methodology Study
}

\author{
Charles Wilf \\ School of Business, Duquesne University, Pittsburgh, USA. \\ Email: wilf@duq.edu \\ Received
}

\begin{abstract}
Debate on the merits of health care reform continues even after passage of the Affordable Care Act of 2010. Poll results confirm a split along political party and associated ideological lines with democrats more supportive and republicans generally opposed to the law. As parts of the law are now subject to increasing scrutiny, it may be instructive to question whether a party-centered or surrogate liberal/conservative dichotomy is the best representation of positions in the health care debate. Q Methodology reveals a more complex set of belief structures, suggesting that a simple dichotomy is misleading in terms of the values that underlie the role of health care in society. Five distinct belief structures were found, each with different concerns as to the purpose and potential benefits of various health care initiatives. In addition, Q Methodology allows for the formation of a common policy space within which all belief structures are independently in agreement in four specific areas. It is argued that this empirically derived consensus can serve as a basis for effective political engagement and policy implementation.
\end{abstract}

Keywords: Belief Structures, Common Policy Space, Q Factor Analysis, Obamacare, Subjectivity

\section{Introduction}

Designed to increase health care coverage for much of the United States population, improve accountability of insurance providers and decrease costs, the Affordable Care Act became law in March, 2010. Some provisions of the law were implemented immediately, and provisions to be implemented throughout the next decade are intended to save more than $\$ 500$ billion in Medicare beneficiary savings alone (Medicare Beneficiary Savings and the Affordable Care Act, 2011) ${ }^{1}$.

Yet the debate over the law's anticipated effectiveness continues, and parts of the law, often referred to as Obamacare, have been challenged by states and are subject to review and possible invalidation. The political landscape that drives these challenges is usually framed as a conflict between liberal and conservative points of view for which we usually substitute the democratic and republican political parties respectively. Recent poll results show the democrats in principle remain in favor the law which expands health care coverage, while the republicans continue to believe that the law will neither improve health care delivery nor reduce costs (Kaiser Health Tracking Poll, 2011).

The seemingly intractable conflict between opposing ideologies as reflected in the polls presupposes a categorization of beliefs that may not reflect more complex differences in the political continuum. Rather than assume that health care beliefs are solely defined and limited to the positions espoused by the major political parties, a systematic investigation of subjective health care priorities may reveal more meaningful points of view. The ability to identify alternative conceptualizations of the health care debate may in turn lead to more appropriate service delivery and cost solutions.

${ }^{1}$ Medicare is the United States government provided health insurance program which covers 1 ) persons over age $65 ; 2$ ) persons under age 65 with certain disabilities; and 3) individuals of any age with specific transplant needs (Medicare Benefits, 2011). As the US population ages and even under the new law, Medicare will become increasingly important in the provision of health care services.
This paper argues that a liberal/conservative dichotomy is overly simplistic and masks a more complex system of belief structures. Through a subjectivity-based analysis of health care opinions that uses Q Methodology, a more incisive array of belief structures can not only pinpoint important differences between these structures, but also suggest a common policy space within which useful and politically feasible health care solutions might occur.

\section{Q Methodology}

Q Methodology uses a specific experimental design to create rank orderings of opinion statements, whereupon factor analysis is performed to ascertain belief structures (Stephenson, 1953; Brown, 1986, 1980; McKeown \& Thomas, 1988). The theory and technique of $\mathrm{Q}$ Methodology may be considered to fall within the more general framework of social cognition (Fiske \& Taylor, 1984). In social cognition and particularly in Q Methodology, a belief structure is a subjective point of view that is 1) communicable, 2) always advanced from a position of selfreference, and 3) amenable to objective analysis since they do have structure and form. Moreover, individuals have a structured set of beliefs that remain stable over time (Cook, Scioli, \& Brown, 1975).

Policy analysis consists of the identification of narratives which describe policy dilemmas (Hampton, 2009; Dryzek, 1990). Durning (1999) and Durning \& Osuna (1994) hold that Q Methodology adds specific value by going beyond a strictly positivist orientation so that analysts can derive deeper understandings. Among these is the creation of a policy space to uncover areas of agreement in the policy debate (Hurd \& Brown, 2004). Wolf (2004), in addition to identifying unique belief structures as a guide to pinpointing policy issues, likewise emphasizes similarities among belief structures as a preferred way to create a more comprehensive understanding of potential common policy options. 
In the current Q Methodology study, a set of 36 health care opinion statements, selected from newspaper articles and magazine articles and letters to the editor, was evaluated by 40 subjects $^{2}$ according to a specific criterion of instruction. According to Nunnally (1978), comparative responses only make sense if the stimuli are from some common domain. Since policy analysts view reasoned debate as the legitimizing basis of the democratic process (Albaek, 1995), published statements in widely available sources are deemed to be representative of this domain. The sample of statements was selected over a period of several weeks from online and print versions of national and local publications. ${ }^{3}$

The selection of sample statements is based on two theoretical criteria. The first is theoretical completeness. The model requires that a comprehensive and representative selection of a particular statement population be included such that the range of possibilities is accounted for (McKeown \& Thomas 1988). The study uses three statement types which are given the labels: "free market"-oriented statements, "socialist" or more collectivist-oriented statements; and more "complex" statements that relate health care issues to larger societal concerns. The free market statements as they appear in the sources are generally less favorable to a proactive health care stance, while the socialist statement subset is more favorably inclined to health care reform. The complex statement subset was included to acknowledge that the public debate about health care is not always independent of other short and long term social, economic and political concerns.

The second theoretical criterion in experiments of this type is the degree of definiteness of the sample statements. Thompson (1966 and discussed in Brown, 1980, and Coke \& Brown, 1976) studied the concept of definiteness in public opinion research. He postulated a hierarchy of definiteness, consisting of three levels-bias, wish and policy-that indicate the intensity of feeling regarding opinion. A bias is a particular interpretation of facts. A wish is a desire for a specified end or course of action. A policy is a belief as to the best means for achieving valued outcomes. In terms of intensity, a wish, or desired end state, implies a bias, or a given state of affairs. Yet the reverse is not true. Likewise, a policy implies a wish, but it represents a more thought-out position; it is more intense, and hence more definite.

Table 1 presents the $3 \times 3$ factorial design indicating the nine statement types to be included.

The model includes the nine opinion statement types each replicated four times for a total of 36 statements in a balanced factorial design. Four statements of each type are included as to facilitate reliability (Brown, 1980). Three examples of statement types are:

This is not about health care. It's about government control. (free market bias statement- $\mathrm{fb}$ )

The American health care system is in bad need of reforms that will eliminate the tragedy of 46 million uninsured people. (socialist wish statement-sw)

If we can enact tort reform that protects patients from reckless

${ }^{2}$ Since the interest of $\mathrm{Q}$ methodology is in the nature of the segments and the extent to which they are similar or dissimilar, the issue of large numbers, so fundamental to most social research, is rendered relatively unimportant. In principle as well as practice, single cases can be the focus of significant research (Brown, 1993).

${ }^{3}$ Main national sources for statements were the Wall Street Journal, The New York Times and Business Week magazine. As the study was conducted in the Pittsburgh region, some statements were extracted from the Pittsburgh Post-Gazette and the Pittsburgh Tribune-Review, the areas two main newspapers.
Table 1.

Q Method opinion statement array.

\begin{tabular}{ccccc}
\hline & & \multicolumn{3}{c}{ Statement Type } \\
\cline { 3 - 5 } & & Free-Market & Socialistic & Complex \\
\hline Intensity & Bias & FB & SB & CB \\
Level & Wish & FW & SW & CW \\
& Policy & FP & SP & CP \\
\hline
\end{tabular}

doctors and doctors from reckless lawyers and juries, we reduce the cost of healthcare tremendously. (complex policy statementср)

In a 9-point "Most Agree-to-Most Disagree” continuum, the methodology requires subjects to place two statements under the Most Agree (value +4 ), and Most Disagree marker (-4), three statements each under the +3 and -3 markers, four statements each under the +2 and -2 markers, and six statements each under the $+1,0$, and -1 markers. Advantages of the forced normal distribution are twofold. First, the same rating scale is used by all respondents, and facilitates intersubjective comparisons. Secondly, the format forces frequent statement comparisons, especially at the extremes (Tetlock et al., 1992). And, it is the extreme cases that most determine the belief structures (Brown, 1980).

It is hypothesized that $\mathrm{Q}$ factor analysis of preference orderings will reveal otherwise nonverbalized belief structures. Moreover, specification of the main effects (free market, socialist and complex statement types) in a model of this type does not guarantee that a set of conclusions will be revealed (Stephenson, 1963). The interest lies in the interpretation of factors (Stephenson, 1964). There are no meanings externally imposed a priori. Rather, the explanation of factors reaches into latent belief systems (Stephenson, 1965), which, in the present case concerns health care belief structures as subjectively construed.

Each statement has a factor score (a unique value on a scale of -4 to +4 , paralleling the original response scale) which indicates the strength of belief of the officials who collectively load on the respective factor. Defining statements for each belief structure (factor) are those whose factor scores differ significantly from the scores of the other belief structures on the same statement. This indicates which statements are not only most important to those within a given factor, but simultaneously whether these statements are unique in importance (either in a positive, negative, or neutral way) to that factor group. A factor score which differs from all others by 2 is significant at the .05 level, and a factor score which differs by three is significant at the .01 level (Brown, 1980).

\section{Findings}

Five unique belief structures were found from the $\mathrm{Q}$ factor analysis, consisting of 30 of the 40 respondents and representing $63 \%$ of the explained variance. ${ }^{4}$ The emergence of these unique structures underscores the difficulty in formulating and implementing acceptable health care policy.

\footnotetext{
${ }^{4}$ The remaining 10 respondents were spread over 5 additional factors. However, they contribute no unique factor scores and were they included they would remove significant factor scores from belief structures 2 and 4 . Demographically there are no dominant characteristics. As such their elimination from the model does not affect the fundamental 5-factor belief structure derivation.
} 


\section{Belief Structure 1-Welfare State Activists}

Ten respondents loaded on this factor which is defined by four statements. Two significant factor scores are positive and two are negative:

Statement 18.

Society should guarantee health care like we guarantee the right to think and pray as you like (sw).

$\begin{array}{llllll}\text { Factor scores: } & 3 & -1 & -2 & 0 & -2\end{array}$

Statement 23.

A public option is the only option for people who have lost jobs due to the economy and do not have affordable health insurance $(s p)$.

$\begin{array}{llllll}\text { Factor scores: } & 1 & -2 & -3 & -1 & -1\end{array}$

Positive factor scores here indicate an entitlement position, implying that government should take a proactive role in health care. Even though the public option was only mildly supported, all other belief structures viewed it negatively, suggesting that even a program that was not well delineated still had support as a matter of principle from this group.

Statement 12 .

It is the responsibility of each person to pay for theirs and their families own health care $(f p)$.

$\begin{array}{llllll}\text { Factor scores: } & \mathbf{- 4} & -1 & 1 & -2 & 1\end{array}$

Statement 11.

The answer to the health care crisis is for people to take responsibility for their own health $(f p)$.

$\begin{array}{llllll}\text { Factor scores: } & \mathbf{- 1} & 1 & 1 & 2 & 3\end{array}$

Statement 12 strongly reinforces the collectivist approach to health care costs, and even the mild rejection of personal responsibility suggests that only activist government intervention can provide adequate protection for the population. Note that three of the four defining statements for the Welfare State Activists are higher order policy level statements, representing well-thought out positions. There are no republicans in this group, and all educational levels are represented (high school graduate through graduate degree). ${ }^{5}$

\section{Belief Structure 2-Future Cost Alarmists}

Eight respondents loaded on this factor, defined by three statements.

Statement 7.

If we don't reduce the growth in health care costs, we'll leave our children with a crushing tax burden (fw).

$\begin{array}{llllll}\text { Factor scores: } & 0 & \mathbf{3} & 0 & -1 & 0\end{array}$

Statement 16.

Forty seven million Americans without health care is a failure of our society. ( $s b)$

$\begin{array}{llllll}\text { Factor scores: } & 3 & \mathbf{1} & -2 & 3 & -1\end{array}$

Statement 25.

As things stand, the health care industry finds it more profitable to treat chronic diseases than to prevent them (cb).

Factor scores: $\quad 2 \quad \begin{array}{lllll}\mathbf{0} & 2 & 3 & -3\end{array}$

Statement 7 largely defines the Future Cost Alarmists. Yet Statements 16 and 25 reinforce this belief structure. They are concerned with the present state of affairs and the factor scores for the Alarmists are significant in their neutrality with factor scores of 1 and 0 compared to the more definitive positions of the other belief structures. The Alarmists are singularly focused on financial hardships to come. While all categories of statements are represented, two of the three statements are bias-type, or the most basic reactive class of expression. No political party

${ }^{5}$ For all belief structures, males and females are almost equally represented. dominates this group and they are older.

\section{Belief Structure 3-Status Quo Advocates}

Seven respondents comprise this factor, defined by five statements, two positive and three negative.

Statement 8.

Because a government-run health insurance company doesn't need to make a profit, privately run companies will be squeezed out of business, and the government would have a monopoly (fw).

Factor scores: $\quad \begin{array}{llllll}-2 & -3 & 3 & -2 & 0\end{array}$

Statement 6.

Universal coverage undercuts the whole notion of cost containment (fw).

Factor scores: $\quad \begin{array}{llllll}-2 & -3 & 2 & -2 & -2\end{array}$

Statement 21.

To compete and win in a global world, no one needs the burden of health insurance shifted from business to government more than American business ( $s p$ ).

Factor scores: $\quad \begin{array}{lllll}0 & -2 & -4 & -1 & 0\end{array}$

Statement 29.

We need to address the economic inequity that underlies our ability to achieve health care outcomes that other societies have achieved (cw).

$\begin{array}{llllll}\text { Factor scores: } & 1 & 1 & \mathbf{- 4} & 2 & 2\end{array}$

Statement 17.

The American health care system is in bad need of reforms that will eliminate the tragedy of 46 million uninsured people (sw).

Factor scores: $\quad 2 \quad 2 \quad \begin{array}{llll}-3 & 2 & 2\end{array}$

Taken together, these statements suggest a distrust of systemic changes in the health care system. Significant factor scores for statements 8 and 16 reflect cost concerns, not unlike those of the Alarmists. However, the negative factor scores for statements 21, 29 and 17 reveal a more universal rejection of change. If costs were the only concern of this group, it is unlikely that statement 21 would be rated so negatively. With one exception, the defining statements are wish, or desired end state type of statements. Status Quo Advocates know what they want and they do not want change. No political party dominates this group, and all respondents have at least a college degree.

\section{Belief Structure 4-Uncertain Interventionists}

Three respondents load on this belief structure which is defined by three statements.

Statement 20.

Health care should not be regarded primarily as a business, with a main goal of increasing shareholder value (sw).

$\begin{array}{llllll}\text { Factor scores: } & -1 & 0 & 1 & 4 & -3\end{array}$

Statement 34.

We are going to have to invest in some kind of a system that is walled off from politics $(c p)$.

$\begin{array}{llllll}\text { Factor scores: } & -1 & 2 & 1 & -3 & 1\end{array}$

Statement 2.

This is not about health care. It's about government control (fb).

Factor scores: $\quad 3 \quad \begin{array}{lllll} & 3 & 4 & \mathbf{0} & 4\end{array}$

This group acknowledges the potential conflict between business interests and the political process, but is decidedly noncommittal regarding the role of government. While other belief structures maintain extreme positions regarding government and its place in health care, the Uncertain Interventionists have yet to reconcile politics and government. And while they 
reject the notion of health care as strictly a business, any alternative vision remains undefined. All categories and all levels of statements are represented, reflecting this comprehensive yet unfocused belief structure. This group has the youngest mean age.

\section{Belief Structure 5-Anti-Government Libertarians}

While only two respondents are represented in this belief structure, three statements with significant positive/non-negative factor scores, and six with significant negative factor scores render it instructive in defining the health care reform parameters. Especially as the debate over rescinding many provisions of the Affordable Care Act intensifies, the quantity of defining statements suggests that this belief structure should not be ignored.

Statement 32.

What the public wants in universal health CARE, not universal health INSURANCE ( $\mathrm{cw})$.

$\begin{array}{llllll}\text { Factor scores: } & 0 & 0 & 1 & 0 & \mathbf{3}\end{array}$

Statement 4.

Medicine is a commodity to be bought and sold ( $f b)$.

Factor scores: $\quad-2 \quad-2 \quad-1 \quad-3 \quad 1$

Statement 8.

Because a government-run health insurance company doesn't need to make a profit, privately run companies will be squeezed out of business, and the government would have a monopoly ( $f w)$.

Factor scores: $\quad-2 \quad-3 \quad 3 \quad-2 \quad 0$

Statement 24.

The public option is the answer for middle class people who are denied affordable coverage due to pre-existing conditions (sp).

Factor scores: $\quad \begin{array}{llllll}1 & 0 & -1 & -1 & -4\end{array}$

Statement 35.

Nobody should have to pay more than a fixed percentage of their income for health insurance premiums $(c p)$.

$\begin{array}{llllll}\text { Factor scores: } \quad 2 & 2 & -1 & -2 & \mathbf{- 4}\end{array}$

Statement 20.

Health care should not be regarded primarily as a business, with a main goal of increasing shareholder value (sw).

$\begin{array}{llllll}\text { Factor scores: } & -1 & 0 & 1 & 4 & -3\end{array}$

Statement 22.

The federal government should provide assistance to states to make their own plans cheaper and cover more people ( $s p)$.

$\begin{array}{llllll}\text { Factor scores: } & -1 & -1 & 0 & 1 & -3\end{array}$

Statement 25.

As things stand, the health care industry finds it more profitable to treat chronic diseases than to prevent them ( $s p)$.

$\begin{array}{llllll}\text { Factor scores: } & 2 & 0 & 2 & 3 & -3\end{array}$

Statement 9.

In healthcare what needs to happen is an emphasis on healthy living $(f p)$.

Factor scores: $\quad \begin{array}{lllll}2 & 3 & 2 & 1 & \mathbf{- 1}\end{array}$

Taken together, this set of defining statements points to distrust and even hostility toward government intervention in general and health care in particular. The two statements with significant positive factor scores suggest a muted if basic skepticism, and there are no policy level statements here. Conversely, two of the six negative statements are at the scale extreme, and three are at the next highest. Additionally, five of the six are policy-level statements, indicating a well-developed belief structure. Anti-government Libertarians are more certain in their rejection of interventionist ideas; even the seemingly non- controversial statement 9 cannot be supported by this group, as it suggests a course of action that in principle could be seen to inhibit personal freedom.

\section{Creating the Common Policy Space}

The emergence of discrete belief structures via Q Methodology highlights the breadth of diverse and often competing positions in the health care debate. This is particularly at issue when different belief structures have significant factor scores on the same statement. Three such statements are found here:

Statement 8.

Because a government-run health insurance company doesn't need to make a profit, privately run companies will be squeezed out of business, and the government would have a monopoly (fw).

Factor scores: $\quad-2 \quad-3 \quad 3 \quad-2 \quad 0$

Statement 20

Health care should not be regarded primarily as a business, with a main goal of increasing shareholder value (sw).

$\begin{array}{llllll}\text { Factor scores: } & -1 & 0 & 1 & 4 & -3\end{array}$

Statement 25.

As things stand, the health care industry finds it more profitable to treat chronic diseases than to prevent them ( $s p$ ).

Factor scores: $\quad 2 \quad 0 \quad \begin{array}{llll}2 & 2 & 3 & -3\end{array}$

In each case the Anti-government Libertarians are at odds with another belief structure. For statement 8, Libertarians disagree with the Status Quo Advocates as the latter resist change while for the Libertarians this is a non-issue. For statement 20, the Libertarians and the Uncertain Interventionists have diametrically opposite positions, while for statement 25 the Libertarians and Future Cost Alarmists are most different in their beliefs. As expected in both cases Libertarians infer that self interest drives health care and the medical establishment. And, as these statements are wish or policy level types, the respective positions are more developed and thus more likely to be defended by those belief structures holding them.

While it may therefore appear that consensus on health care reform is unattainable, there is equal empirical support for agreement by all belief structures among a set of four statements. It is these commonalities that form the basis for a common policy space and subsequent political engagement. There are two statements with which all belief structures either agree or are neutral:

Statement 19.

No American family should be bankrupted by catastrophic health care bills (sw).

$\begin{array}{llllll}\text { Factor scores: } & 4 & 4 & 1 & 3 & 1\end{array}$

Statement 31.

Business cannot keep absorbing soaring health care costs and keep passing them on to their employees $(\mathrm{cw})$.

$\begin{array}{llllll}\text { Factor scores: } & 0 & 1 & 2 & 1 & 1\end{array}$

Statement 19 can be interpreted as a fundamental baseline in the health care debate, as all five belief structures either strongly or mildly agree. While statement 31 does not command the same intensity of support, no belief structure disagrees with this concept. As both statements are wish or desired end state types, there is genuine concern across the subjectivity spectrum regarding an outcome that is sensitive to both potential individual and organizational hardship. A common policy space begins with an awareness of this fundamental agreedupon position.

There are two additional statements with which all belief 
structures either disagree or are neutral.

Statement 3.

Health care is a luxury, just like living in a nice neighborhood or driving a nice car $(f b)$.

$\begin{array}{llllll}\text { Factor scores: } & -4 & -1 & -3 & -4 & 0\end{array}$

Statement 1.

Health care is socialism, and socialism is not an American value $(f b)$.

Factor scores: $\quad \begin{array}{llllll}-3 & -4 & 0 & -4 & 0\end{array}$

Statement 3 emphasizes the universal prioritization of health care common to all belief structures, and even the Libertarians do not reject this position. The statement on socialism, included so as to make the domain as comprehensive as possible, is also either strongly rejected or ignored. The health care debate has often been infused with inflammatory ideology to advance political agendas. However the analysis reveals an inverse association or indeed no association between health care and an alternative societal paradigm. It is also significant that both statements are fact types or lower order statements. All belief structures show a common position at this most basic level, and do not involve higher order goals or methods for their attainment.

\section{Conclusion}

Q Methodology reveals a set of distinct belief structures that go beyond differences found in political polls. Five belief structures were derived from the analysis and indicate that underlying ideas and concerns about health care reform cover a more complex range than previously indicated. While labels and hence ideologies such as liberal or conservative have been repeatedly applied to the health care debate, Q Methodology shows that these labels are simplistic at best, and potentially misleading. It may seem, for example, that the conservative label might equally apply to the Status Quo Advocates and the Anti-Government Libertarians. But a review of their defining statements indicates important differences between them. Consider Statement 29:

We need to address the economic inequity that underlies our ability to achieve health care outcomes that other societies have achieved (cw).

Factor scores: $\quad \begin{array}{lllll}1 & 1 & -4 & 2 & 2\end{array}$

The Status Quo Advocates are adamantly opposed since this involves change, while the Libertarians take a position more like the Welfare State Activists, the Future Cost Alarmists and the Uncertain Interventionists, who could hardly be considered conservatives. Yet one could argue that the Libertarians react positively to this statement because in their belief structure it represents an imperative for individual self-sufficiency on this issue, just as self-sufficiency drives their other responses.

Equally important, Q Methodology has shown that despite deep differences in underlying belief structures, there is a common policy space that can serve as a practical starting point for discussing health care service delivery. Protection from catastrophic financial loss, a concern for accelerating business health care expenditures, and a belief that access to health care is a basic necessity are fundamental premises that every belief structure, from Welfare State Activists to Anti-Government Libertarians can support. As the health care debate continues and likely intensifies as challenges to the Affordable Care Act are presented, policy prescriptions that begin with these few preliminary yet politically acceptable ideas may have a better likelihood of generating meaningful and permanent health care reform than more comprehensive programs that put opposing belief structures against each other.

\section{References}

Albaek, E. (1995). Between knowledge and power: Utilization of social science in public policy making. Policy Sciences, 28, 79-100. doi:10.1007/BF01000821

Brown, S. R. (1993). A primer on Q Methodology. Operant Subjectivity, 16, 91-138.

Brown, S. R. (1986). Q technique and method. In W. D. Berry, \& M. S. Lewis-Beck (Eds.), New tools for social scientists (pp. 57-76). Beverly Hills: Sage.

Brown, S. (1980). Political subjectivity: Applications of Q Methodology in political science. New Haven: Yale University Press.

Cook, T. J., Scioli, F. P., \& Brown, S. R. (1975). Experimental design and Q Methodology: Improving the analysis of attitude change. Political Methodology, 2, 51-69.

Dryzek, J. S. (1990). Discursive democracy: Politics, policy, and political science. Cambridge: Cambridge University Press.

Durning, D. (1999). The transition from traditional to postpositivist policy analysis: A role for Q-methodology. Journal of Policy Analysis and Management, 18, 389-410. doi:10.1002/(SICI)1520-6688(199922)18:3<389::AID-PAM4>3.0.C $\underline{\mathrm{O} ; 2-\mathrm{S}}$

Durning, D., \& Osuna, W. (1994). Policy analysts’ roles and value orientations: An empirical investigation using Q Methodology. Journal of Policy Analysis and Management, 13, 629-657. doi:10.2307/3325491

Fiske, S., \& Taylor S. (1984). Social cognition. New York: Random House.

Hampton, G. (2009). Narrative policy analysis and the integration of public involvement in decision making. Policy Sciences, 42, 227-242. doi:10.1007/s11077-009-9087-1

Hurd, R. C., \& Brown, S. R. (2004/2005). The future of the Q Methodology movement. Operant Subjectivity Journal of the International Society for the Scientific Study of Subjectivity, 28, 58-75.

Kaiser Health Tracking Poll (July 2011). URL (last checked 17 October 2011) http://www.kff.org/kaiserpolls/8209.cfm

McKeown, B. B., \& Thomas, D. (1988). Q Methodology-Quantitative applications in the social sciences. Beverly Hills: Sage.

Medicare Beneficiary Savings and the Affordable Care Act (2011). URL (last checked 17 October 2011)

http://www.healthcare.gov/law/resources/reports/affordablecareact.ht $\mathrm{ml}$

Medicare Benefits (2011). URL (last checked 17 October 2011) http://www.medicare.gov/navigation/medicare-basics/medicare-bene fits/medicare-benefits-overview.aspx

Nunnally, J. C. (1978). Psychometric theory (2nd ed.). New York: McGraw Hill.

Stephenson, W. (1953). The study of behavior: Q-technique and its methodology. Chicago: University of Chicago Press.

Stephenson, W. (1963). Independency and operationism in Q-sorting. Psychological Record, 13, 269-272.

Stephenson, W. (1964). Application of Q method to measurement of public opinion. Psychological Record, 14, 265-273.

Stephenson, W. (1965). Definition of opinion, attitude and belief. Psychological Record, 15, 281-288.

Tetlock, P. E., Peterson, R., McGuire, C., Chang, S., \& Feld, P. (1992). Assessing political and group dynamics: A test of the groupthink model. Journal of Political and Social Psychology, 63, 403-425. doi:10.1037/0022-3514.63.3.403

Thompson, G. C. (1966). The evaluation of public opinion. In B. Berelson, \& M. Janowitz (Eds.), Reader in public opinion and communication, (2nd ed., pp. 7-12). New York: The Free Press.

Wolf, A. (2004). The bones of a concourse. Operant Subjectivity Journal of the International Society for the Scientific Study of Subjectivity, 27, 145-165. 